\title{
Architektur und Psychoanalyse
}

\section{Erhard Taverna}

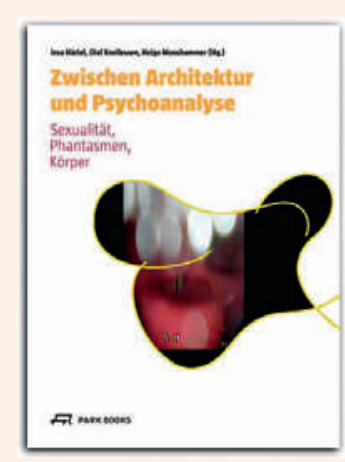

Insa Härtel, Olaf Knellessen, Helge Mooshammer (Hrsg.)

Zwischen Architektur und Psychoanalyse

Zürich: Park Books; 2012

224 Seiten, 57.90 CHF

ISBN 978-3-9060-2707-4
Architekturpsychologie ist eine längst etablierte Kulturtechnik. Eine andere Frage ist: Wie viel Psychoanalyse steckt in der Architektur, wie viel Architektur in der Psychoanalyse? Ein Bezug, der neugierig macht und Erwartungen weckt. Am Anfang stand ein Symposium zum Thema Transparenz und Intimität, organisiert 2009 vom Psychoanalytischen Seminar Zürich (PSZ) zusammen mit der Architektur-Zeitschrift Hochparterre. 2012 erschien das Buch zum Thema mit dem Titel «Zwischen Architektur und Psychoanalyse», grafisch sehr schön gestaltet und um weitere Beiträge aus dem Angloamerikanischen erweitert. Die Herausgeber möchten mit eigenen Worten den Austausch zwischen den zwei Bereichen ausbauen und vertiefen. Sie bedauern, dass seit Alexander Mitscherlichs Buch «Die Unwirtlichkeit unserer Städte» von 1965 trotz naheliegender Berührungspunkte in der deutschsprachigen Literatur nur wenig dazu publiziert worden sei.

Das PSZ ist den psychoanalytischen Vorgaben von Sigmund Freud verpflichtet. Freuds Regeln der räumlichen Positionen eines analytischen Settings, als strukturierendes Element seines Sprechzimmers, dienen als Indikator für die Beziehung zur Architektur. Seine Diagramme und Skizzen werden wie architektonische Grundrisse und Schnitte gelesen, seine Metaphern wörtlich in die Baukunst übertragen. Aus der topografischen Lesart psychischer Prozesse, wie Schichtungen oder Erinnerungsspuren, sollen neue Betrachtungsweisen der architektonischen Schnittstellen zwischen Innerlichkeit und Äusserlichkeit resultieren. Mit dem Bild eines Hauses untermalte Freud wiederholt seine Gedanken, etwa in seiner vielzitierten Aussage «nicht Herr im eigenen Haus» oder eine Betrachtung wie: «Situationen wie die des Bauherrn, der bei einem Architekten eine Villa nach seinem Geschmack und Bedürfnis bestellt (...), sind mit den Bedingungen der Psychoanalyse im Grunde nicht vereinbar.» Psychiatrische Begriffe, wie Arbeiten am Widerstand des Patienten, Übertragung und Gegenübertragung, Identifikation oder Angst, führen zu Denkformen der Bauwelt, markiert durch Begriffe wie Sichtbarkeit, Stoff, Grenzen und Auftragsverhältnis. Freud hat seine Praxis des Ausgrabens, Enthüllens und Aufdeckens häufiger mit der Arbeit des Archäologen verglichen. Das Re-Konstruieren sei aber in der Sprechstunde nicht das Ziel, sondern nur eine Vorarbeit. Wände sind Hilfsvorstellungen, es gibt im Haus vernachlässigte und unaufgeräumte Bereiche, in denen vielleicht Leute wohnen, von denen man lieber nichts wissen will. Sein analytischer
Weg zu dieser Konstruktion wird mit dem planenden Verfahren, basierend auf Geometrie, Statik und Mathematik, verglichen. Die Gemeinsamkeit liege dann darin, dass Freuds Gerüst aus Worten wie das Gerüst des Renaissance-Architekten Brunelleschi zum integralen Bestandteil des Kuppelbaus werde. Die Bezüge sind fantasiereich und verschlungen. $\mathrm{Ob}$ es um eine romanische Krypta, eine Neuinterpretation der Analyseprotokolle vom «Wolfsmann», ob es um Spaltungen, Brüche, Höhlungen, Höfe, Enklaven und versperrte Türen geht, alles wird, mit Berufung auf Derrida, Lacan oder Foucault, lustvoll und üppig aufgetragen, zu gemeinsamen Symbolen einer neuen Sichtbarkeit, zu Architextur erklärt. Wie Körper und Bewegung wird auch der gebaute Umgebungsraum libidinös besetzt. Der letzte Beitrag kritisiert die moderne, sterile Stadtplanung: «Die fetischisierte Stadt ist ein Versuch, das unbewusste Wissen zu verleugnen, dass das Fremde (...) unsere Grenzen ungehindert überschreiten kann (...) Die Menschen in den Städten sollen nie tatsächlich zusammentreffen.» Das schliesst nahtlos an Mitscherlich an: «Die hochgradig integrierte alte Stadt hat sich funktionell entmischt (...) Die Unwirtlichkeit ist niederdrückend.» Wenn die Literaturwissenschaftlerin, fast 50 Jahre später, zur gleichen Diagnose kommt, ist das deprimierend. Doch den gesellschaftlichen Heilkräften der Medizin und Architektur sind sehr enge Grenzen gesetzt. Ihnen gemeinsam ist, dass sie den widersprüchlichen Ansprüchen nicht genügen können.

Das hochkarätige Team will neue Perspektiven eröffnen. Die Beiträge sind ambitiös, rhetorisch brillant, kühn und poetisch. Teilweise auch überspannt und inhaltlich weniger als formal überzeugend. Es sprechen acht Medienkünstler, Philosophen, Kulturund Literaturwissenschaftler, ein Psychoanalytiker und eine Historikerin. Vier weitere haben Architektur studiert, doch nur einer, Christian Kerez, Professor für Architektur und Entwurf an der ETH Zürich, hat seine Visionen in reale Bauten umgesetzt, unter anderem in das Schulhaus Leutschenbach. Was Architekten von Sigmund Freud oder umgekehrt lernen könnten bleibt letztlich, trotz bunter Argumentationsketten und literarischer Sprachakrobatik, unklar. Auch inspirierende Designskizzen, Modelle, Studien und preisgekrönte Installationen kompensieren nicht die abwesende Praxis. Ob Sigmund Freud als alleiniger Vertreter seiner Richtung genügt, müssen andere beurteilen. 